\title{
Role of risk factors for major coronary heart disease events with increasing length of follow up
}

\author{
S G Wannamethee, A G Shaper, P H Whincup, M Walker
}

\begin{abstract}
Background-It has been suggested that the predictive value of certain risk factors for coronary heart disease (CHD) measured at one point in time diminishes with increasing length of follow up.

Designs and methods-The relation was examined between a wide range of risk factors and the risk of major CHD events over 15 years' total (cumulative) follow up and for three separate five year periods (0-5.0, 5.1-10.0, and 10.1-15.0 years) in men with and without diagnosed CHD in a large prospective study of 7735 men aged 40-59 years.
\end{abstract}

Setting-General practices in 24 towns in the UK.

Results-The cumulative CHD event rate for all men was $9.4 / 1000$ person-years for the 15 years of follow up. In men with no recall of a diagnosis of $\mathrm{CHD}$, the established risk factors-serum total cholesterol, high density lipoprotein cholesterol, systolic and diastolic blood pressure, physical activity, body mass index (BMI), alcohol intake, diabetes mellitus, parental history, and evidence of CHD on chest pain questionnaire or on ECG-were predictive of CHD events occurring in the three specific periods after baseline measurement. Blood pressure (systolic and diastolic) was still predictive of events occurring 10.1-15.0 years later with some attenuation in the relative risk associated with systolic blood pressure. The risks associated with blood glucose and serum insulin concentration, factors measured with greater imprecision, attenuated with longer follow up and were not predictive of events occurring 10.1-15.0 years later. In men with recall of diagnosed CHD, the absolute risk was very high $(38.8 / 1000$ person-years); only cigarette smoking, BMI, total cholesterol, and serum insulin were predictive of $\mathrm{CHD}$ events occurring 10.1-15.0 years later.

Department of Primary Care and Population Sciences, Royal Free Hospital School of Medicine, Rowland Hill Street, London NW3 2PF, UK S G Wannamethee A G Shaper

P H Whincup

M Walker

Correspondence to:

Dr Wannamethee.

Accepted for publication 26 October 1998

Consion-In men without recall diagnosed CHD most major risk factors measured in middle age predict risk of CHD events occurring in up to 15 years of follow up, both cumulatively and in the three separate five year periods. Risk factors measured at one point in time in middle age may be regarded as reliable indicators for long term prognosis of major CHD events on a group basis, despite the changes that may take place in these risk factors in some individuals during prolonged follow up.

(Heart 1999;81:374-379)
Keywords: coronary heart disease, risk factors; epidemiology

In most large scale prospective cardiovascular studies, assessment of risk factors is based on single measurements at initial screening. Single measurements of biological factors (for example, blood pressure) are subject to considerable intra-individual variation, and risk factor status in individuals at baseline may change during the course of follow up. The predictive value for coronary heart disease (CHD) of risk factors measured at one point in time is likely to be influenced by duration of follow up which varies in different prospective studies from 5-30 years. Several studies have examined the role of the three major risk factors-serum total cholesterol, cigarette smoking, and systolic blood pressure-in short and long term prediction; these factors are generally found to be independent predictors of CHD over long term cumulative follow up. ${ }^{1-8}$

Fewer studies have examined whether the predictive value of these risk factors measured at baseline changes with increasing duration of follow up and whether they remain predictive of events occurring at specific periods later in follow up. Indeed there is a suggestion that the hazard ratio (relative risk) associated with certain risk factors (for example, smoking and systolic blood pressure) diminish with long term follow up. ${ }^{23}$ The behaviour of other coronary risk factors in this respect has received less attention and few studies have examined whether the predictive role is similar in men with and without established CHD. This paper examines: (1) the role of a wide range of established risk factors in relation to major CHD events (fatal and non-fatal) occurring over a total (cumulative) period of 15 years' follow up; (2) whether risk factors measured at baseline predict major CHD events at three specific five year periods of follow up (0-5.0, 5.1-10.0, and 10.1-15 years later); and (3) whether the predictive roles vary according to the absence or presence of doctor diagnosed CHD.
Subjects and methods

The British regional heart study is a prospective study of cardiovascular disease involving 7735 men aged $40-59$ years at enrolment selected from the age-sex registers of one group general practice in each of 24 towns in England, Wales, and Scotland between January 1978 and June 1980. The criteria for selecting the towns, the general practice, and the subjects as well as the methods of data collection have been reported. ${ }^{9}$ Each man completed a standard questionnaire 
administered by the research nurses which included questions on smoking habits, alcohol intake, and medical history. Several physical measurements were made, and blood samples (non-fasting) were taken for measurement of biochemical and haematological variables. Details of the classification method for smoking, alcohol intake, and physical activity have been described. ${ }^{9-11}$ The men provided information on parental status (alive/dead) and on the cause of parental death (heart trouble, high blood pressure, stroke, etc). Parental history of death from heart trouble is defined as men who reported that a parent had died from "heart trouble". ${ }^{12}$

\section{BIOLOGICAL FACTORS}

Blood pressure

The London School of Hygiene sphygmomanometer was used to measure blood pressure twice in succession with the subjects seated and the arm supported on a cushion. The mean of the two readings was used in the analysis and all blood pressure readings were adjusted for observer variation within each town. ${ }^{13}$

Blood lipids

All the blood samples were obtained in the non-fasting state between 08:30 and 18:30. Detailed information on blood lipid measurements have been published. ${ }^{14}$

Blood glucose

Glucose was analysed using a commercially available automated analyser (Technicon SMA 12/60; Technicon Instruments, Tarrytown, New York, USA). Diurnal variation in glucose levels was modest. ${ }^{1516}$

Insulin

Serum insulin concentration was determined by a two site enzyme linked immunosorbent assay (ELISA). Insulin measurements were available for men in 18 towns $(n=5661)$. Adjustments were made for the marked diurnal variation. ${ }^{17}$

PRE-EXISTING DISEASE

The men were asked to recall a doctor diagnosis of angina or myocardial infarction, diabetes, and a number of other disorders listed on the questionnaire. The World Health Organisation (Rose) chest pain questionnaire was administered to all men at the initial examination ${ }^{18}$ and a three orthogonal lead ECG was recorded at rest.

The men were separated into three groups according to the evidence of CHD present at screening: (1) no evidence of CHD on WHO chest pain questionnaire, ECG or recall of a doctor diagnosis of CHD ( $n=5792)$; (2) no recall of a doctor diagnosis of $\mathrm{CHD}$ but with (a) angina or possible myocardial infarction on WHO chest pain questionnaire, or (b) ECG evidence of possible or definite myocardial ischaemia or possible myocardial infarction with no recall of a doctor diagnosis of CHD ( $\mathrm{n}=1521)$; (3) men with recall of a doctor diagnosis of CHD (myocardial infarction or angina) ( $\mathrm{n}=422)$. This latter group is referred to as having "diagnosed CHD".
FOLLOW UP

All men, whether or not they showed evidence of ischaemic heart disease at initial examination, were followed up for all cause mortality and for cardiovascular morbidity. ${ }^{19}$ Information on death was collected through the established "tagging" procedures provided by the National Health Service registers in Southport (England and Wales) and Edinburgh (Scotland). By December 1995, all men had been followed up for at least 15 years (range 15.5-18 years). Fatal events were defined as death from CHD (International Classification of Diseases ninth revision codes 410-414) as the underlying cause. A major non-fatal CHD eventmyocardial infarction/heart attack - was diagnosed according to WHO criteria which included any report of myocardial infarction accompanied by at least two of the following criteria: (1) history of severe prolonged chest pain; (2) ECG evidence of myocardial infarction; and (3) cardiac enzyme changes associated with myocardial infarction.

\section{STATISTICAL METHODS}

Cox proportional hazards model was used to assess the independent contributions of the risk factors to the risk of major CHD events and to obtain the relative risks adjusted for age and the other risk factors. ${ }^{20}$ For the categorical and binary variables the results obtained from the multiple regression model are presented as relative risks by the levels of risk factors. For the quantitative (continuous) biological variables, such as systolic and diastolic blood pressure, serum total cholesterol, and high density lipoprotein (HDL) cholesterol, the men were divided into quartiles of the distribution and the relative risks are presented for the top quartile versus bottom quartile. For body mass index (BMI) the men were divided into five groups on the basis of absolute levels $(<22$, $22-24,24-26,26-28$, and $\left.>28 \mathrm{~kg} / \mathrm{m}^{2}\right)$. p Values (tests for trends) in tables 2-4 were obtained fitting these quantitative variables in their continuous form. Cut off points were used for blood glucose ( $\geqslant 6.2 \mathrm{mmol} / \mathrm{l}$; top fifth versus rest) and insulin ( $\geqslant 33.76 \mathrm{mU} / \mathrm{L}$; top decile versus rest) as our earlier reports have shown a threshold effect, ${ }^{16}$ and these were fitted as dichotomous variables. In tables 2 and 3 light and moderate drinkers have been combined for comparison with occasional drinkers.

In the adjustment age, BMI, systolic blood pressure, and cholesterol were fitted continuously. Smoking (three groups-never, exsmoker, current smoker), physical activity (five groups - none, occasional, light, moderate and moderately vigorous/vigorous), alcohol intake (four groups-none, occasional, light/ moderate, and heavy), diabetes (yes/no), and parental history of heart trouble (yes/no) were fitted as categorical variables. Subjects with missing values for covariates in the various adjustments using Cox's model were excluded from that analysis. In the specific analyses examining the relation between blood glucose and risk of major CHD events, all men with history of diabetes or baseline blood glucose concentrations $\geqslant 11.1 \mathrm{mmol} / 1$ were excluded. 
Table 1 Pre-existing CHD status and rates/1000 person-years, and age adjusted relative risk of CHD over 15 years' cumulative follow up and by specific period of follow up

\begin{tabular}{|c|c|c|c|}
\hline & \multicolumn{3}{|l|}{ CHD status } \\
\hline & $\begin{array}{l}\text { None } \\
(n=5792)\end{array}$ & $\begin{array}{l}\text { Evidence but no doctor } \\
\text { diagnosis }(n=1521)\end{array}$ & $\begin{array}{l}\text { Doctor diagnosed } \\
(n=422)\end{array}$ \\
\hline \multicolumn{4}{|l|}{ Total 15 years'cumulative follow up } \\
\hline Rate/1000 (n) & $7.0(563)$ & $12.6(249)$ & $38.8(171)$ \\
\hline Age adjusted $\mathrm{RR}(95 \% \mathrm{CI})$ & 1.0 & $1.7(1.5$ to 2.0$)$ & 4.6 (3.8 to 5.5$)$ \\
\hline \multirow{2}{*}{\multicolumn{4}{|c|}{$\begin{array}{l}\text { Specific period of follow up } \\
0-5.0 \text { years }\end{array}$}} \\
\hline & & & \\
\hline Number at risk & 5792 & 1521 & 422 \\
\hline Rate/1000 (n) & $5.1(146)$ & $11.2(82)$ & $38.4(72)$ \\
\hline Age adjusted RR (95\% CI) & 1.0 & $2.0(1.6$ to 2.7$)$ & $5.9(4.4$ to 7.9$)$ \\
\hline \multicolumn{4}{|l|}{$5.1-10$ years } \\
\hline Number at risk ${ }^{\star}$ & 5544 & 1404 & 331 \\
\hline Rate/1000 (n) & $7.4(199)$ & $13.9(92)$ & $41.8(60)$ \\
\hline Age adjusted RR (95\% CI) & 1.0 & $1.7(1.4$ to 2.2$)$ & $4.4(3.3$ to 6.0$)$ \\
\hline \multicolumn{4}{|l|}{$10.1-15$ years } \\
\hline Number at risk ${ }^{\star}$ & 5182 & 1237 & 251 \\
\hline Rate/1000 (n) & $8.8(218)$ & $13.0(75)$ & $35.8(39)$ \\
\hline Age adjusted RR (95\% CI) & 1.0 & $1.4(1.1-1.8)$ & $3.5(2.5-5.0)$ \\
\hline
\end{tabular}

^Men who died or developed major CHD before the specific follow up period were excluded. $\mathrm{MI}$, myocardial infarction; RR, relative risk; CI, confidence intervals.

Analysis involving insulin was based on 5661 men. To test whether the ratio hazard changed with time, a time dependent explanatory variable $-\mathrm{X}=\mathrm{X}(\mathrm{t})$ where $\mathrm{X}(\mathrm{t})=\log (\mathrm{t})^{\star}$ risk factor - was fitted in the model. ${ }^{21}$ At each event time, subjects still alive just before each event time would have their $\mathrm{X}$ value changed accordingly.

\section{Results}

During the total cumulative 15 year follow up period of the 7735 men in the study there were 983 major CHD events (cases) (9.4/1000 person-years). In the $0-5.0$ year period there were 300 cases $(8.0 / 1000$ person-years $)$, in the 5.1-10.0 year period 351 cases occurred (10.0/ 1000 person-years), and in the $10.1-15.0$ year period there were 332 cases $(10.5 / 1000$ person-years).

CHD STATUS

The absolute rates of CHD increased about twofold in men with evidence of CHD but with

Table 2 Cardiovascular risk factors and adjusted relative risk of major CHD events over 15 years' cumulative duration of follow up in 7198 men with no diagnosed CHD (799 cases) and with available data on all lifestyle covariates

\begin{tabular}{|c|c|}
\hline Coronary risk factors & $\begin{array}{l}\text { Adjusted relative risk } \\
(95 \% \mathrm{CI})\end{array}$ \\
\hline \multicolumn{2}{|l|}{ Lifestyle and pre-existing disease $†$} \\
\hline \multicolumn{2}{|l|}{ Smoking } \\
\hline Ex $(v$ never $)$ & $1.5(1.2 \text { to } 2.8)^{\star \star \star}$ \\
\hline Current ( $v$ never) & $2.3(1.9 \text { to } 2.9)^{\star \star \star \star}$ \\
\hline $\mathrm{BMI}\left(\geqslant 28 v<22 \mathrm{~kg} / \mathrm{m}^{2}\right)$ & $1.8(1.4 \text { to } 2.3)^{\star \star \star \star}$ \\
\hline Alcohol (light/moderate $v$ occasional) & $0.8(0.7 \text { to } 0.9)^{\star \star}$ \\
\hline Physical activity (moderate $v$ none) & $0.5(0.4 \text { to } 0.7)^{\star \star \star \star}$ \\
\hline Parental history (yes/no) & $1.5(1.3 \text { to } 1.8)^{\star \star \star \star}$ \\
\hline Pre-existing CHD (no diagnosis) & $1.6(1.4 \text { to } 1.8)^{\star \star \star \star}$ \\
\hline Diabetes (yes/no) & $2.2(1.5 \text { to } 3.3)^{\star \star}$ \\
\hline \multicolumn{2}{|l|}{ Biological factors $\ddagger$} \\
\hline Systolic blood pressure $\$$ & $1.9(1.5 \text { to } 2.4)^{\star \star \star}$ \\
\hline Diastolic blood pressure $₫$ & $1.8(1.4 \text { to } 2.3)^{\star \star \star}$ \\
\hline Cholesterols & $2.5(2.0 \text { to } 3.2)^{\star \star \star \star}$ \\
\hline HDL cholesterol§ & $0.6(0.5 \text { to } 0.7)^{\star \star \star \star}$ \\
\hline Glucose $(\geqslant 6.2 \mathrm{mmol} / 1 v$ rest $)$ & $1.2(0.9$ to 1.4$)$ \\
\hline Insulin (top decile $v$ rest) & $1.5(1.2 \text { to } 1.9)^{\star \star \star}$ \\
\hline \multicolumn{2}{|c|}{$\begin{array}{l}\text { Test for difference/trend: }{ }^{\star} \mathrm{p}<0.05 ;{ }^{\star \star} \mathrm{p}<0.01 ;{ }^{\star \star \star} \mathrm{p}<0.001 \text {. } \\
\text { †Adjusted for age, lifestyle factors, diabetes and pre-existing } \\
\text { CHD (without diagnosis). } \\
\text { †Adjustments made in addition for systolic blood pressure and } \\
\text { total cholesterol. } \\
\text { §Top quartile } v \text { bottom quartile. }\end{array}$} \\
\hline
\end{tabular}

no recall of a diagnosis of CHD, and about fivefold in men with recall of doctor diagnosed CHD (table 1). The increased risk associated with pre-existing CHD (with and without recall) was seen in all three specific time periods of follow up-0-5.0, 5.1-10, and 10.1-15.0 years-although there was some attenuation in the relative risk with increasing duration of follow up in both groups of men with evidence of CHD. Since men with diagnosed CHD showed exceptionally high rates, we have examined the role of established coronary risk factors and the risk of major CHD events by specific period of follow up separately in men with and without doctor diagnosed CHD. Men with evidence of CHD but with no recall of a diagnosis of CHD are included in the group not having diagnosed CHD. However, in tables 2 and 3 adjustment is made for this pre-existing CHD.

RISK FACTORS IN MEN WITH NO DIAGNOSED CHD Table 2 shows the relation between potential risk factors (lifestyle characteristics, preexisting disease, and biological factors) and subsequent risk of major CHD events during the total cumulative 15 year follow up period.

Personal characteristics and pre-existing disease Smoking, BMI, alcohol, physical activity, parental history, pre-existing CHD (no doctor diagnosis), and diabetes were predictive of major CHD events, even after adjustment for each of the other lifestyle characteristics and pre-existing disease (table 2).

\section{Biological factors}

For the biological factors additional adjustments were made for systolic blood pressure and serum total cholesterol because they are both strong risk factors for CHD and correlate with the other biological factors. In the analysis involving diastolic blood pressure, systolic blood pressure was not included in the adjustment and vice versa. Serum total cholesterol, HDL cholesterol, systolic and diastolic blood pressure, and insulin were significantly and strongly predictive of major CHD events over 15 years. Hyperglycaemia showed a weak and non-significant relation with CHD, although our previous report based on shorter follow up (9.5 years' cumulative) showed a significant relation. ${ }^{16}$

\section{SPECIFIC PERIOD OF RISK}

We examined the relation between risk factors and risk of major CHD in men with no recall of diagnosed CHD by specific periods of follow up, in order to assess whether these factors are predictive of events occurring later in the follow up period, for example, 5.1-10.0 years and 10.1-15.0 years after screening (table 3 ). This analysis avoids the effects of cumulative assessment in which strong effects in the early period may be carried through to later periods. Most of the risk factors examined were predictive of events occurring 10.1-15.0 years after screening. Diabetes was still predictive at 10-15 years; the lack of statistical significance is probably caused by the small numbers and 
Table 3 Cardiovascular risk factors and adjusted relative risk of major $C H D$ events by specific period of follow up in men with no diagnosed CHD with available data on all lifestyle covariates

\begin{tabular}{|c|c|c|c|}
\hline & \multicolumn{3}{|c|}{ Specific period of follow up (years) } \\
\hline & $0-5.0$ & $5.1-10$ & $10.1-15$ \\
\hline Number of events/subjects & $224 / 7198$ & $284 / 68389$ & $291 / 6319$ \\
\hline Rates/1000 person-years & 6.4 & 8.7 & 9.6 \\
\hline \multicolumn{4}{|l|}{ Lifestyle and pre-existing diseaset } \\
\hline \multicolumn{4}{|l|}{ Smoking ( $v$ never) } \\
\hline Ex & 1.9 & $1.1(0.7$ to 1.5$)$ & $1.7(1.2 \text { to } 2.6)^{\star \star}$ \\
\hline Current & 2.9 & $1.6(1.2 \text { to } 2.2)^{\star \star}$ & $3.0(2.1 \text { to } 4.3)^{\star \star \star}$ \\
\hline $\mathrm{BMI}\left(\geqslant 28 v<22 \mathrm{~kg} / \mathrm{m}^{2}\right)$ & 1.4 & $1.7(1.1 \text { to } 2.7)^{\star \star}$ & $2.3(1.4 \text { to } 3.7)^{\star \star \star}$ \\
\hline Alcohol (light/moderate $v$ occasional) & 0.9 & $0.7(0.6 \text { to } 1.0)^{\star}$ & $0.7(0.5 \text { to } 0.9)^{\star}$ \\
\hline Physical activity (moderate $v$ none) & 0.6 & $0.5(0.3 \text { to } 0.8)^{\star \star}$ & $0.5(0.3 \text { to } 0.9)^{\star \star}$ \\
\hline Parental history (yes/no) & 1.5 & $1.6(1.3 \text { to } 2.0)^{\star \star \star}$ & $1.5(1.1 \text { to } 1.9)^{\star \star \star}$ \\
\hline Pre-existing CHD (no diagnosis) & 1.8 & $1.6(1.3 \text { to } 2.1)^{\star \star \star}$ & $1.3(1.0 \text { to } 1.7)^{\star}$ \\
\hline Diabetes (yes/no) & 1.9 & $2.8(1.6 \text { to } 5.2)^{\star \star \star}$ & $1.7(0.7$ to 3.8$)$ \\
\hline \multicolumn{4}{|l|}{ Biological factors $\ddagger$} \\
\hline Systolic blood pressure & 3.0 & $1.8(1.2 \text { to } 2.6)^{\star \star}$ & $1.5(1.0,2.1)^{+}$ \\
\hline Diastolic blood pressure $\$$ & 2.0 & $1.7(1.2 \text { to } 2.6)^{\star \star}$ & $1.7(1.2 \text { to } 2.5)^{\star}$ \\
\hline Cholesterol】 & 2.3 & $2.6(1.8 \text { to } 3.7)^{\star \star \star}$ & $2.7(1.9 \text { to } 3.9)^{\star \star \star}$ \\
\hline HDL cholesterol\$ & 0.6 & $0.5(0.4 \text { to } 0.8)^{\star \star \star \star}$ & $0.5(0.4 \text { to } 0.8)^{\star \star}$ \\
\hline Glucose $(\geqslant 6.2 \mathrm{mmol} / 1 v$ rest $)$ & 1.1 & $1.4(1.0 \text { to } 1.8)^{\star}$ & $1.0(0.7$ to 1.3$)$ \\
\hline Insulin (top decile $v$ rest) & 2.2 & $1.3(0.9$ to 1.9$)$ & $1.4(0.9$ to 2.1$)$ \\
\hline
\end{tabular}

Test for difference/trend: ${ }^{+} \mathrm{p}=0.05 ;{ }^{\star} \mathrm{p}<0.05 ;{ }^{\star \star} \mathrm{p}<0.01 ;{ }^{\star \star \star} \mathrm{p}<0.001$

†Adjusted for age, lifestyle factors, diabetes, and pre-existing CHD.

$\ddagger$ Adjustments made in addition for systolic blood pressure and total cholesterol.

$§$ Top quartile $v$ bottom quartile.

\Men who died or developed major CHD before the specific follow up period were excluded.

the high rate of attrition in diabetic subjects in the earlier years. For both pre-existing CHD and for diabetes there was some attenuation in risk over time. For systolic blood pressure there was some attenuation over time but raised systolic blood pressure at screening remained associated with increased risk. A test for risk trend with systolic blood pressure within the 10.1-15.0 year period was of marginal significance $(p=0.05)$, as the increase in risk with increasing systolic blood pressure in the period was not progressive as seen in the earlier follow up periods. The hazard ratios associated with serum insulin and serum glucose was attenuated and was not significantly predictive of events occurring 10.1-15.0 years later. A test for interaction with period of follow up was only significant for insulin and systolic blood pressure, indicating that the hazard ratio associated with these two factors diminished with increasing follow up.

\section{MEN WITH DIAGNOSED CHD}

The absolute rates of major CHD were very high in men with a recall of a doctor diagnosis of CHD. Many of the major risk factors were

Table 4 Cardiovascular risk factors and adjusted t relative risk of major CHD events during 15 years'follow up and by specific period of follow up in 414 men with diagnosed CHD with available data on all lifestyle covariates

\begin{tabular}{|c|c|c|c|c|}
\hline & \multirow{2}{*}{$\frac{\text { Cumulative }}{15 \text { years }}$} & \multicolumn{3}{|c|}{ Specific period of follow up (years) } \\
\hline & & $0-5.0$ & $5.1-10.0$ & $10.1-15$ \\
\hline Number of cases/subjects & $169 / 414$ & $72 / 414$ & $59 / 3249$ & $38 / 246$ \\
\hline \multicolumn{5}{|l|}{ Smoking } \\
\hline Ex ( $v$ never $)$ & $1.9^{\star}$ & 0.8 & $4.0^{\star}$ & $3.7^{+}$ \\
\hline Current ( $v$ never) & $2.5^{\star \star}$ & 1.3 & $3.8^{\star}$ & $6.4^{\star}$ \\
\hline $\mathrm{BMI}\left(\geqslant 28 v<22 \mathrm{~kg} / \mathrm{m}^{2}\right)$ & $2.6^{\star \star}$ & $4.3^{\star \star}$ & 1.7 & $3.0^{\star}$ \\
\hline Systolic blood pressure $\neq \subseteq$ & $1.3^{+}$ & 1.2 & $1.7^{+}$ & 1.0 \\
\hline Diastolic blood pressure $\ddagger \varnothing$ & $1.7^{\star \star}$ & $1.9^{\star \star}$ & $2.7^{\star \star}$ & 0.6 \\
\hline Cholesterol $\neq 5$ & $1.5^{+}$ & $1.6^{\star \star}$ & 1.0 & 2.3 \\
\hline Insulin $\neq \subseteq$ (top decile $v$ rest) & $1.8^{\star}$ & 1.4 & $2.6^{\star}$ & 1.8 \\
\hline
\end{tabular}

Test for difference/trend: ${ }^{+} 0.05 \leqslant \mathrm{p} \leqslant 0.08 ;{ }^{\star} \mathrm{p}<0.05 ;{ }^{\star \star} \mathrm{p}<0.01 ;{ }^{\star \star \star} \mathrm{p}<0.001$.

†Adjusted for age, lifestyle factors, and diabetes.

†Adjustments made in addition for systolic blood pressure and/or cholesterol.

§Top quartile $v$ bottom quartile.

ๆMen who died or developed major CHD before the specific follow up period were excluded also predictive in this group over the cumulative 15 year period-smoking, BMI, diastolic blood pressure, serum insulin, and, to a lesser extent, cholesterol and systolic blood pressure (table 4). When examined by specific period of follow up, only smoking, BMI, total cholesterol, and insulin remained predictive 10.1-15 years later (table 4). Given the very small number of subjects and cases, we are more concerned with the trends than with the statistical significance of these findings. Physical activity, alcohol intake, parental history, HDL cholesterol, and blood glucose showed little association with risk of further CHD events in this group of men (data not shown).

\section{Discussion}

In an overview of 11 long term follow up prospective studies ranging from 15 to 30 years it was concluded that the three major coronary risk factors-serum total cholesterol, blood pressure, and cigarette smoking-are strong long term independent risk factors for $\mathrm{CHD}{ }^{1}$ While these factors remain significant independent predictors using cumulative follow up, few of the studies reviewed have assessed whether the hazard ratio associated with these risk factors measured at baseline changes with increasing duration of follow up and whether they remain predictive of events occurring at specific periods later in follow up. In this study of middle aged British men most of the risk factors examined were predictive over 15 years' cumulative follow up, with little or slight attenuation with increasing follow up. The three major risk factors remained predictive of events occurring in the specific period 10.115.0 years later, although for blood pressure there was some attenuation.

Although our findings are based on only 15 years' follow up, the results are similar to those observed in the Finnish study using follow up of 25 and 30 years, which assessed the predictive value of baseline coronary risk factors over time. ${ }^{23}$ The Finnish study found smoking and total cholesterol measured at baseline to be predictive of CHD events occurring both early and late during the cumulative follow up. However, systolic blood pressure tended to lose its predictive power after 20 years. It is likely that with longer follow up the predictive power for blood pressure would become more attenuated. Most studies find systolic blood pressure to attenuate with increasing follow up time with little prediction after $15-20$ years. ${ }^{23} 8$

In contrast, the strength of the association with serum total cholesterol changed little with time. Most other studies have found serum total cholesterol to be predictive of events occurring late in follow up-that is, 15-25 years later. ${ }^{238}$ Several other large cohorts of middle aged men have indicated that the strength of the association of baseline serum total cholesterol with coronary risk changes very little during follow up, ${ }^{22}$ and the Whitehall study ${ }^{24}$ suggested that the predictive value may even increase with follow up.

Smoking remained strongly predictive of events occurring later in follow up, although the strongest effect was seen in the early follow 
up as observed in the Finnish study. ${ }^{2}$ This is to be expected given that a certain proportion of subjects tend to give up smoking during the course of follow up. In this study about $44 \%$ of the current smokers at baseline were still smoking $16-18$ years later. While most studies show the effects of smoking to decline with increasing follow up, some studies find smoking to be predictive of events occurring later in follow up while in others no association was seen. The long term prediction of smoking may depend on the percentage of subjects who give up. In the Finnish study ${ }^{2}$ light smoking at baseline did not predict events late in follow up but heavy smoking was still predictive; this could possibly be explained by the large proportion of light smokers who had given up smoking. In the Swedish study smoking was not predictive of events occurring after five years. ${ }^{8}$ The long term effects of smoking assessed at baseline is likely to be dependent on the rate of giving up during the course of follow up.

OTHER RISK FACTORS

In contrast to the other major risk factors, BMI tended to increase its predictive power during follow up. This has been observed in several other studies and suggests that the long term effects of obesity are starting to take its toll in later life..$^{38}$ Few studies have examined the change in hazard ratio associated with other recognised risk factors, but most of them, particularly HDL cholesterol, physical activity, diabetes, alcohol intake, and parental history, remained predictive of events occurring 10-15 years later with little attenuation over time. However, insulin and blood glucose were not predictive of events occurring late in follow up. These variables are measured with greater imprecision and greater intra-individual variation than others, such as serum total cholesterol.

\section{TRACKING}

The long term predictive power of risk factors is likely to be dependent on both the precision of measurement as well as the tracking of risk factors over time. In the Finnish study, ${ }^{23} \mathrm{BMI}$ and total cholesterol were both shown to have high tracking. In the present study both these factors remained strongly predictive of CHD events in later follow up with little attenuation; for BMI the predictive power tended to increase, which may also reflect the long term effects of being overweight. Blood pressure was shown to have moderate tracking and this is consistent with the slight attenuation in risk associated with systolic blood pressure observed in this and other studies. ${ }^{238}$

\section{REPEATED MEASUREMENTS}

In the majority of prospective studies a single assessment of risk factor is used in long term prediction. A question often raised in epidemiological studies is whether it is necessary to obtain multiple baseline measurements or repeated measurements over time for biological variables in order to assess the long term predictive role of risk factors. These proce- dures reduce regression dilution bias which may arise because of misclassification based on a single measurement. ${ }^{25}$ Several studies have confirmed that the use of repeated measurements of risk factors over time increase the statistical predictive power of risk factors for CHD in long term follow up. ${ }^{26-28}$ However, our study, in agreement with others, indicates that a single measurement of risk factor assessed at baseline is a good indicator of events occurring 10-15 years later and should not be disregarded in long term follow up.

MEN WITH DIAGNOSED CHD

Although men with diagnosed CHD have about four times the risk of major CHD events compared to men without diagnosed CHD, some of the major risk factors - smoking, BMI, diastolic blood pressure, total cholesterol, insulin, and, to a lesser extent, systolic blood pressure-are still predictive in these men over 15 years' cumulative follow up. However, only smoking, BMI, total cholesterol, and insulin remained predictive with increasing duration of follow up, although for total cholesterol and insulin the results were not significant, presumably because of the small numbers.

\section{CONCLUSION}

In men without recall of a doctor diagnosis of CHD the predictive role of most major risk factors for CHD measured in middle aged men persists with long term follow up. In men with a recall of a doctor diagnosis of CHD only a few factors (for example, smoking and BMI) predict major CHD events in the 10.1-15 year period of follow up. Risk factors measured at one point in time in middle age may be regarded as reliable indicators for long term prognosis of major CHD events in groups of subjects, despite the changes which may take place in these risk factors in some individuals during prolonged follow up.

The British regional heart study is a British Heart Foundation research group and receives support from the Department of Health. SGW is a British Heart Foundation research fellow.

1 Kornitzer M, Goldberg R, eds. Contribution of long term follow-up to the prediction of coronary heart disease. Cardiology 1993;82:85-8.

2 Pekkanen J, Nissinen A, Puska P, et al. Risk factors and 25 year risk of coronary heart disease in a male population with a high incidence of the disease: the Finnish cohorts of the seven countries study. BMF 1989;299:81-5.

3 Pekkanen J, Tervahauta M, Nissinen A, et al. Does the predictive value of baseline coronary risk factors change over a 30-year follow-up. Cardiology 1993;82:181-90.

4 Goldbourt U, Yaari S, Medalie JH. Factors predictive of long-term coronary heart disease mortality among 10059 long-term coronary heart disease mortality among 10059
male Israeli civil servants and municipal employees. Cardiology 1993;82:100-21.

5 Kannel WB, Larson M. Long term epidemiologic prediction of coronary heart disease. The Framingham experience. Cardiology 1993;82:137-52.

6 Kornitzer M, Dramaix M, Beriot I, et al. Twenty five year mortality follow-up in the Belgian bank study. Cardiology 1993;82:153-71

7 Stamler J, Dyer AR, Shekelle RB, et al. Relationship of baseine major risk factors to coronary and all cause mortality and to longevity. Findings from long term follow-up of Chicago cohorts. Cardiology 1993;82:191-222.

8 Welin L, Eriksson H, Larsson B, et al. Risk factors for coronary heart disease during 25 years of follow-up. Cardiology 1993;82:223-8.

9 Shaper AG, Pocock SJ, Walker M, et al. British regional heart study: cardiovascular risk factors in middle-aged men in 24 towns. BMF 1981;283:179-86.

10 Shaper AG, Wannamethee G, Walker M. Alcohol and mortality: explaining the U-shaped curve. Lancet 1988;ii: 1268-73. 
11 Shaper AG, Wannamethee G, Weatherall R. Physical activity and ischaemic heart disease in middle-aged men. $B$ ity and ischaemic heart

12 Phillips AN, Shaper AG, Pocock SJ, et al. Parental death from heart disease and the risk of heart attack. Eur Heart $\mathcal{F}$ 1988;9:243-51.

13 Bruce NG, Shaper AG, Walker M, et al. Observer bias in blood pressure studies. F Hypertens 1988;6:374-80.

14 Thelle DS, Shaper AG, Whitehead TP, et al. Blood lipids in middle-aged British men. Br Heart f 1983;49:205-13.

15 Pocock SJ, Ashby D, Shaper AG, et al. Diurnal variations in serum biochemical and haematological measurements. $f$ Clin Pathol 1989;42:172-9.

16 Perry IJ, Wannamethee SG, Whincup PH, et al. Asymptomatic hyperglycaemia and major ischaemic heart disease events in Britain. F Epidemiol Comm Health 1994;48:53842.

17 Perry IJ, Wannamethee SG, Whincup PH, et al. Serum insulin and incident coronary heart disease in middle-aged British men. Am f Epidemiol 1996;144:224-34.

18 Cook DG, Shaper AG, Macfarlane PW. Using the WHO (Rose) angina questionnaire in cardiovascular epidemiology studies. Int f Epidemiol 1989;18:607-13.

19 Walker M, Shaper AG. Follow-up of subjects in prospective studies based in general practice. $\mathcal{F} R$ Coll Gen Pract 1984; 34:365-70.

20 Cox DR. Regression models and life tables (with discussion) f R Stat Soc B 1972;34:187-220.
21 SAS Technical Report P-217. SAS/STAT Software: The PHREG Procedure Vision 6. SAS Institute 1991.

22 Ragland DR, Brand RJ. Coronary heart disease mortality in the Western collaborative group study: follow-up experience of 22 years. Am f Epidemiol 1988;127:462-475.

23 Stemmerman GN, Chyou PH, Kagan A, et al. Serum cholesterol and mortality among Japanese-American men: theHonolulu (Hawaii) heart program. Arch Intern Med 1991;151:969-72.

24 Shipley MJ, Pocock SJ, Marmot MG. Does plasma cholesterol concentration predict mortality from coronary heart disease in elderly people? 18 years follow-up in Whitehall disease in elderly people? 18
study. BMf 1991;303:89-92.

25 Macmahon S, Peto R, Cutler J, et al. Blood pressure, stroke and coronary heart disease I. prolonged differences in blood pressure: prospective observational studies corrected for the regression dilution bias. Lancet 1990;335:765-74.

26 Menotti A, Seccareccia F, Lanti M, et al. Time changes in predictability of coronary heart disease in an Italian aging population. Cardiology 1993;82:172-80.

27 de Vries CL, Feskens EJM, de Lezenne Coulander C, et al. Repeated measurements of serum cholesterol and blood pressure in relation to long-term incidence of myocardial pressure in relation to long-term inci
infarction. Cardiology 1993;82:89-99.

28 Reed D, Benfante R. Lipid and lipoprotein predictors of coronary heart disease in elderly men in the Honolulu heart program. Ann Epidemiol 1992;2:29-34. 